\title{
Los servicios públicos como derechos humanos
}

\author{
Diego Dal Santo \\ Universidad Nacional de La Pampa, Facultad de Ciencias Económicas y Jurídicas, \\ Santa Rosa, Argentina \\ $\triangle$ diego1010ar@yahoo.com.ar \\ 望-1 Fecha de recepción: 2/10/2019 Fecha de aceptación: 30/12/2019
}

\begin{abstract}
Cómo citar este artículo: Dal Santo, D. (2020). "Los servicios públicos como derechos humanos". Revista Perspectivas de las Ciencias Económicas y Jurídicas. Vol. 10, $\mathrm{N}^{\circ} 2$ (julio-diciembre). Santa Rosa: FCEyJ (UNLPam); EdUNLPam; pp. 169-179. ISSN 2250-4087, e-ISSN 2445-8566

DOI http://dx.doi.org/10.19137/perspectivas-2020-v10n2a08
\end{abstract}

Resumen: El propósito de este trabajo es reconocer a los servicios públicos como derechos humanos, contemplados tanto en instrumentos internacionales de derechos humanos como también en nuestra Constitución Nacional y el Código Civil y Comercial. La experiencia demuestra que no siempre la intervención de los privados redunda en la mejor y más efectiva prestación de los servicios. Para esto, solo basta revisar la historia reciente de nuestro país, a partir de principios de la década del 90 con la privatización de las empresas públicas. Su reestatización no solo refuerza esa idea, sino que además demuestra el fracaso de los entes de control creados al efecto. La participación activa de las asociaciones de consumidores y usuarios será clave, no sólo para lograr un precio accesible sino, y sobre todo, una prestación de calidad. En un país con los actuales índices de desocupación, pobreza e indigencia, el acceso a tarifas con precios razonables y servicios de calidad mejoraría de manera sustancial la calidad de vida. Deberá estudiarse una manera más efectiva de otorgar subsidios para las clases media y baja y establecer así los precios de las tarifas, que dependerá, por ejemplo, de los salarios del grupo familiar, si son beneficiarios de algún plan social, barrios donde habitan, etc.

Palabras claves: servicios públicos; tarifas; subsidios; privatizaciones; derechos humanos; tratados internacionales; Constitución Nacional; Código Civil y Comercial. 


\title{
Public services as human rights
}

\begin{abstract}
The purpose of this work is to recognize public services as human rights, contemplated both in international human rights instruments and also in our National Constitution and the Civil and Commercial Code. Experience shows that private intervention does not always result in the best and most effective provision of services. For this, we will only have to review the recent history of our country, beginning in the early 90s with the privatization of public companies. Its re -statization not only reinforces that idea but also demonstrates the failure of the control entities created for this purpose. The active participation of consumer and user associations will be key, not only to achieve an affordable price but, above all, a quality service. In a country with the current rates of unemployment, poverty and indigence, access to affordable rates and quality services would improve substantially in the quality of life. A more effective way of granting subsidies for the middle and lower classes should be studied and thus establish the prices of the rates, which will depend, for example, on the salaries of the family group, if they are beneficiaries of some social plan, neighborhoods where they live, etc.
\end{abstract}

Keywords: public services; rates; subsidies; privatizations; human rights; international deals; National Constitution; Civil and Commercial Code.

\section{Serviços públicos como direitos humanos}

Resumo: O objetivo deste trabalho é reconhecer os serviços públicos como direitos humanos, contemplados tanto em instrumentos internacionais de direitos humanos quanto em nossa Constituição Nacional e no Código Civil e Comercial. A experiência mostra que a intervenção privada nem sempre resulta na melhor e mais eficaz prestação de serviços. Para isso, basta revisar a história recente de nosso país, desde o início dos anos 90, com a privatização de empresas públicas. Sua reformulação não apenas reforça essa idéia, mas também demonstra a falha das entidades de controle criadas para esse fim. A participação ativa de associações de consumidores e usuários será fundamental, não apenas para obter um preço acessível, mas, acima de tudo, um serviço de qualidade. Em um país com taxas atuais de desemprego, pobreza e indigência, o acesso a preços razoáveis e serviços de qualidade melhoraria substancialmente a qualidade de vida. Devese estudar uma maneira mais eficaz de conceder subsídios para as classes média e baixa, estabelecendo assim os preços das tarifas, que dependerão, por exemplo, dos salários do grupo familiar, se eles são beneficiários de algum plano social, vizinhança onde moram, etc.

Palavras chave: serviços públicos; preços subsídios; privatizações; direitos humanos; tratados internacionais; Constituição Nacional; Código Civil e Comercial.

\section{Introducción}

La idea de que cada ser humano tiene derechos que deben ser respetados en todo momento y lugar, por el simple hecho de ser persona es muy reciente. Será por eso que al neoliberalismo, al mercado y a la economía globalizada les cuesta comprender este razonamiento.

Luego de la Segunda Guerra Mundial se decía "Ya no habrá gente de segunda, ni maltrato para nadie. Habrá justicia, trabajo y un nivel de vida digno para 
todos. Ningún niño morirá de pobreza. La comunidad internacional vigilará el progreso vigoroso en todos estos aspectos" (Limpens, 1999, p. 1).

Es en esa época cuando surge la "Declaración Universal de Derechos Humanos de la Organización de Naciones Unidas" (1948), y a su vez, cada región fue dictando instrumentos similares de igual reconocimiento: la Declaración Americana de los Derechos y Deberes del Hombre (1948) y la Convención Americana sobre los Derechos Humanos -Pacto de San José de Costa Rica (1969)- de la OEA; la Carta Africana de Derechos Humanos y de los Pueblos (1981); Convención Europea de Derechos Humanos (1953), entre otras.

Estos diferentes instrumentos reconocieron, según las épocas, tres generaciones de derechos humanos, que brevemente podríamos definir de la siguiente manera:

- Los de la primera generación: los derechos civiles y políticos son los más antiguos en su desarrollo normativo. Nacen de la lucha contra el abuso de poder por parte de las autoridades. Reclaman libertades para el individuo frente al Estado o cualquier autoridad. Imponen al Estado el deber de respetarlos siempre; son derechos absolutos; solo pueden ser limitados en los casos previstos en la Constitución; su titular es, en los derechos civiles, todo ser humano y en los derechos políticos todo ciudadano; su reclamo corresponde al propio individuo.

- Los de la segunda generación: los derechos económicos, sociales y culturales son derechos de contenido social para procurar mejores condiciones de vida. Nacen de las luchas sociales a partir de la revolución industrial. Amplían la esfera de responsabilidad del Estado; imponen un "deber hacer" positivo por parte del Estado en dos esferas: la satisfacción de necesidades (por ejemplo, construir hospitales) y la prestación de servicios (por ejemplo, educación básica gratuita); su titular es el individuo en comunidad, que se asocia para su defensa, por ejemplo, en sindicatos; son derechos relativos, su reclamo es mediato e indirecto, está condicionado a las posibilidades económicas del país y son legítimas aspiraciones de la sociedad.

- Los de la tercera generación: los derechos de los pueblos o derechos de solidaridad conforman un conjunto todavía un tanto confuso e indefinido. Nacen de problemas y conflictos supranacionales como cuestiones medioambientales, las guerras, el reclamo de autodeterminación y desarrollo digno de los pueblos indígenas y de las naciones del tercer mundo. Requieren para su cumplimiento de prestaciones positivas (hacer, dar) y negativas (no hacer), tanto de un Estado como de toda la comunidad internacional.

Con lo expuesto hasta aquí me pregunto si el Estado argentino a partir de los aumentos de 2016 en adelante, incumple con su obligación respecto a la prestación de servicios públicos de calidad y con tarifas accesibles para todos sus habitantes, violando así derechos humanos. 
La situación fue variando desde principios de la década del 90 con la privatización de los servicios públicos, pasando por la crisis del 2001, las reestatizaciones en el gobierno de Kirchner (adoptando las empresas la figura de la sociedad anónima) y los aumentos desmedidos de tarifas en la presidencia de Macri.

Debemos partir de la premisa que "El bien común consiste en la suma de las condiciones de la vida social que permite que los grupos sociales y cada uno de los miembros, consigan con mayor facilidad y plenitud su propia perfección" (Maljar, 1998, pp. 98-99). En efecto, tal como señala Cormick (2012, p. 234): "El Estado debe (...) concentrar esfuerzos principalmente en: a) Promover el acceso a dicho servicio para un número cada vez mayor de habitantes, ampliando la red; b) Permitir el real acceso de un número cada vez mayor de habitantes por medio de un costo accesible de dichos servicios que no genere exclusiones económicas en su uso".

\section{Regulación}

Veamos la reglamentación que se hace en el derecho nacional de los servicios públicos. "En nuestro país, el Preámbulo de la Constitución Nacional ha fijado los grandes fines o metas de nuestra Nación que se podrían resumir en el concepto de bien común. Esos fines, añade finalmente nuestro Preámbulo, son 'para nosotros, para nuestra posteridad (...) etc.'” (Maljar, 1998, p. 101).

Se introdujo a los servicios públicos en la esfera de derechos y garantías de nuestro derecho constitucional con la reforma de 1994 a través de dos vías:

1) La incorporación del art. 42 dentro del capítulo "Nuevos Derechos y Garantías", que produce el retorno de la vinculación entre el servicio público y derechos y garantías de los particulares, y la incorporación del usuario como sujeto privilegiado de ese régimen; y

2) La inclusión de los tratados internacionales de derechos humanos, incorporados a través del art. 75, inc. 22.

Es en estas normas donde encontramos el sustento constitucional de los derechos del usuario de los servicios públicos y del deber jurídico del Estado de garantizar su cobertura.

De esta manera, la norma constitucional designa un sujeto acreedor (el usuario, no solo el efectivo sino también el eventual o potencial) y dos deudores solidariamente responsables (el Estado y el prestador del servicio).

Así, el art. 42 CN debe ser analizado en conjunto con el art. $43 \mathrm{CN}$, que brinda protección a través de la figura del amparo, a quienes se les reconoce legitimación procesal en reclamos de incidencia colectiva a través de asociaciones y del Defensor del Pueblo.

Por su parte, la Constitución incorpora los tratados internacionales en su art. 75, inc. 22, protegiendo de esta manera que "Toda persona tiene derecho a un nivel 
de vida adecuado que le asegure, así como a su familia, la salud y el bienestar y en especial la alimentación, el vestido, la vivienda, la asistencia médica y los servicios sociales necesarios" (art. 25.1 de la Declaración Universal de Derechos Humanos).

En su art. 75, inc. 23, la Constitución establece entre las atribuciones del Congreso, "legislar y promover medidas de acción positiva que garanticen la igualdad de oportunidades y de trato, y el pleno goce y ejercicio de los derechos reconocidos por esta Constitución y los tratados internacionales vigentes sobre derechos humanos, en particular respecto de los niños, las mujeres, los ancianos y las personas con discapacidad".

Los tratados internacionales previstos en el art. 75, inc. 22, mencionan de diferentes maneras a los servicios públicos, a veces, bajo esta denominación, y a veces de manera más genérica, aunque inequívoca; así en el art. XXXVI de la Declaración Americana de Derechos y Deberes del Hombre, vinculado con el deber de pagar impuestos se establece "Toda persona tiene el deber de pagar impuestos establecidos por la ley para el sostenimiento de los servicios públicos", lo que traería aparejado, como contrapartida, el derecho a recibir los servicios necesarios para el desarrollo personal y social. Pero aun cuando el individuo no pudiese pagar por el servicio, según nuestra jurisprudencia, el suministro de agua potable no puede ser interrumpido, toda vez que la falta de pago no puede condicionar la prestación de un servicio público esencial de carácter irremplazable. ${ }^{(1)}$

Las normas de la Declaración Universal, del Pacto Internacional, de la Declaración Americana, y de la Convención Internacional son aún más específicas, pues aunque no todas utilicen literalmente la categoría de servicio público, todas se refieren al "derecho a un nivel de vida adecuado", donde se incluye expresamente a la familia; la primera menciona "bienestar", la segunda se refiere a "condiciones de existencia", y la última muy concretamente se refiere a los "servicios destinados al uso público".

El reconocimiento de los servicios públicos como derechos humanos también ha traído implicancias en cuanto a la aplicación del principio de "igualdad ante la ley, igual protección ante la ley y no discriminación", ya que la Corte Interamericana de Derechos Humanos ha establecido la obligatoriedad que pesa en cabeza de los Estados, de respetar y garantizar los derechos humanos, sin discriminación alguna y en una base de igualdad, derivada de la obligación de los mismos de adoptar medidas positivas para revertir o cambiar situaciones discriminatorias existentes en sus sociedades, en perjuicio de determinado grupo de personas.

La cuestión de los servicios públicos y las tarifas también aparece en el nuevo Código Civil y Comercial, que entró en vigencia el 1 de agosto de 2015. En primer

(1) Ver fallo de CCont. y Adm, sala I de San Miguel de Tucumán (2010).. 
lugar, el art. $1^{\circ}$ establece "Los casos que este Código rige deben ser resueltos según las leyes que resulten aplicables, conforme la Constitución Nacional y los tratados de derechos humanos en los que la República sea parte...". El art $2^{\circ}$, en cuanto a la interpretación, establece "La ley debe ser interpretada teniendo en cuenta sus palabras, sus finalidades, las leyes análogas, las disposiciones que surgen de los tratados sobre derechos humanos...". A esta relación y remisión, se la denominó "Diálogo de fuentes" y "Constitucionalización del derecho privado".

Por su parte, los arts. 51 y 52, dentro de los "Derechos y actos personalísimos", dicen, respectivamente "La persona humana es inviolable y en cualquier circunstancia tiene derecho al reconocimiento y respeto de su dignidad", y "La persona humana lesionada en su intimidad personal o familiar, honra o reputación, imagen o identidad, o que de cualquier modo resulte menoscabada en su dignidad personal, puede reclamar la prevención y reparación de los daños sufridos....".

El art. 1093 define "contrato de consumo" como aquel que "es el celebrado entre un consumidor o usuario final con una persona humana $o$ jurídica que actúe profesional u ocasionalmente o con una empresa productora de bienes o prestadora de servicios, pública o privada, que tenga por objeto la adquisición, uso o goce de los bienes o servicios por parte de los consumidores o usuarios, para su uso privado, familiar o social".

El agua, energía y gas como derechos humanos poseen reconocimiento directo, también, en diferentes resoluciones de la Organización de Naciones Unidas, donde se establece que deben estar al alcance de todos, con un costo razonable, que su acceso "no debe limitar la capacidad de pagar por otras necesidades esenciales, como alimentación, vivienda y atención a la salud".

El acceso a estos servicios redundaría en reducir la pobreza y mejorar las condiciones de vida en general, ya que tienen incidencia directa en la alimentación, salud y educación. Y esto, sin dudas, en nuestra dignidad como seres humanos, reconocida en los arts. 51 y 52, 279 y 1004 del Código Civil y Comercial.

\section{Situación en los últimos años}

El alcance general de los servicios públicos es una cuenta pendiente de los diferentes gobiernos, nacionales y provinciales, problemática que se relaciona con grandes obras de infraestructura y los fondos con qué realizarlas, lo que justificaría la toma de deuda, por ejemplo, con organismos internacionales. La falta de inversión impidió el mantenimiento y la expansión de los diferentes servicios. Claro que de a poco (muy de a poco) se fue incluyendo a la población en los diferentes servicios; pero no en los índices contractuales establecidos con las empresas prestatarias, donde lo que se priorizó fue el mayor rédito económico posible, lo que demuestra que los servicios públicos de carácter esenciales (agua, cloacas, gas y electricidad) no pueden quedar supeditados a los 
vaivenes típicos de la actividad empresarial ni a los intereses de cada gobierno. La decisión del Estado de transferir a manos privadas la obligación de prestar estos servicios no significa que pueda desentenderse de la responsabilidad que le cabe de garantizarlos en condiciones de igualdad a toda su población.

Y un dato más que no debemos soslayar. Durante la década del 90, y en la actualidad nuevamente, el Fondo Monetario Internacional llegó al país con sus conocidas y ya fracasadas recetas. Entre ellas, los aumentos de tarifas (y privatización de las empresas estatales) y demás políticas que siempre tienen foco en las clases media y baja de la población, y suelen ser algunas de las exigencias de cumplimiento previo, y obligatorio, a los desembolsos de dinero.

A esta altura, creo que no resultan infundadas mis dudas sobre las verdaderas y ciertas ventajas que hoy ofrece el libre juego del mercado, en cuanto a su teórica virtud de permitir acceder al mejor precio y calidad, ya que la experiencia argentina en materia de servicios públicos demostraría lo contrario (Galina, 2009, p. 145).

Se dijo:

... las empresas privatizadas que brindarán un servicio público de enorme trascendencia social, deberán tener presente que su actuación primordial y fundamental se vinculará directamente con las finalidades públicas, y muchas veces deberán dejar de lado su pretensión de lucro y beneficio económico cuando se encuentre comprometido el bien común. Por tratarse de empresas en gran medida "públicas" la motivación fundamental de su actuación no puede ser el lucro, sino la satisfacción de determinadas necesidades sociales que pueden requerir en ocasiones actuaciones rigurosamente "antieconómicas" (Maljar, 1998, p. 90).

Si bien el otorgamiento de concesiones a manos privadas es uno de los modelos posibles para financiar la expansión de servicios públicos esenciales a todos los sectores de la población, son varios los ejemplos que dan cuenta que ni las privatizaciones ni la presencia de capitales extranjeros garantizan per se una mayor eficiencia en la prestación. Muchos menos aún estas condiciones garantizan el acceso de los sectores más vulnerables de la población a esos servicios.

El censo del año 2010 marca detalles sin duda reveladores al respecto:

1) Combustible utilizado principalmente para cocinar: sobre un total de 12.171 .675 hogares censados, 6.834 .327 poseen gas de red; 54.908 utilizan zeppelin; 351.808 gas en tubo; 4.558 .737 gas en garrafa; 32.928 utilizaban electricidad y 322.915 leña o carbón.

2) Electricidad: sobre 12.174.069, 11.898 .143 por red; 128.802 por generación propia y 147.124 aún no tenían.

3) Y por último, en cuando a la provisión y procedencia de agua: sobre un total de $12.171 .675,6.473 .354$ poseen cloacas; 2.992 .460 a cámara séptica y pozo ciego; 2.190.295 a pozo ciego; 199.095 un hoyo en la tierra y 316.471 sin retrete.

También podemos apreciar los siguientes datos: sobre el total de hogares censados; 11.075.555 poseen recolección de residuos al menos dos veces por semana; 
9.663.314 poseen transporte público al menos a 300 metros y 11.544 .598 poseen alumbrado público. ${ }^{(2)}$

Desde inicio de 2016, y hasta octubre de 2018, nuestro país verificó aumentos acumulados promedio de $2057 \%$ en gas natural, $1941 \%$ en energía eléctrica y de casi $1000 \%$ en el servicio de agua potable; la garrafa de 10, 12 y 15 kg aumentó $122 \%, 677 \%$ en peajes, $375 \%$ en el boleto del tren, $332 \%$ en colectivos de corta distancia y un $177 \%$ en subtes, pasando de una incidencia sobre el salario muy baja del costo tarifario cercana al $6 \%$ a una sustantivamente mayor, de $23,5 \%{ }^{(3)}$

Desde la quita de los subsidios, las ganancias de las empresas fueron gigantescas al haberse dolarizado los precios; se dijo que los aumentos tarifarios redundarían en mayores inversiones y mejoras de los diferentes servicios: algo que tampoco se reflejó en la realidad. "El impuestazo, la baja de los salarios públicos, la recesión, no hicieron otra cosa que hundir más a los hundidos y agregarle a este sector varias personas más" (Galina, 2009).

Estos aumentos desmedidos provocaron, en todo el país, una ola de juicios por acción de clases que solicitaban volver al cuadro tarifario anterior. Si bien el marco de este trabajo excede su análisis detallado, uno de los más emblemáticos el "Fallo Cepis" es: (CSJN, 2016):(4)

En el año 2002, posterior a la gran crisis del 2001, la actuación de la población civil fue importante. "Todas las medidas ilegítimas que adoptó el gobierno para conseguir aumentos tarifarios fueron frenadas por los usuarios, quienes a través de organizaciones que los agrupan o de la representación por parte de distintas Defensorías del Pueblo supieron combinar las estrategias necesarias para actuar exitosamente. Así, las primeras dos convocatorias a audiencias públicas con el objetivo de analizar el aumento tarifario fueron suspendidas por acciones judiciales interpuestas por numerosas ONG de consumidores y usuarios y por la Defensoría del Pueblo de la Ciudad de Buenos Aires" (Garrote, 2007, pp. 381-382).

\section{Conclusión}

No se reclama que los servicios públicos sean gratuitos, ya que sin dudas, su generación provoca costos, que, de mínima, deberían recuperarse. Lo que se pone sobre el tapete es su accesibilidad general. La política de subsidios

... no deja de ser una política con beneficios directos e indirectos: entre los más importantes, la reducción de costos que mejoran la competitividad comercial o industrial, y la posibilidad de, al tener que abonar menos en tarifas en servicios públicos, permitir a los usuarios volcar ese dinero en la economía, generándose mayor consumo, lo que redunda en más puestos de trabajo y mayor recaudación fiscal, entre otros (Cormick, 2012, p. 241).

(2) Ver datos en https://www.indec.gob.ar/

(3) Ver datos en Observatorio de Políticas Públicas de la Universidad Nacional de Avellaneda: http://undav.edu.ar/general/recursos/adjuntos/22096.pdf

(4) Ver fallo completo aquí: http://www.eldial.com/nuevo/pdf_fallos/AA98D9.pdf 


\section{Entonces,}

La utilización de los recursos presupuestarios a la hora de fijar los sucesivos presupuestos anuales no deja de ser una definición política del Congreso Nacional. Es por eso que entendemos que así como a la hora de recaudar los principios de igualdad y proporcionalidad exigen que los ciudadanos "...deben contribuir al sustento del gobierno, lo más aproximadamente posible, en proporción con sus capacidades respectivas; esto es, en proporción con la renta que ellos gozan bajo la protección del Estado", es igual de razonable que a la hora de destinar los fondos recaudados, el Estado oriente los mismos a aquéllos que menos tienen, lo que comúnmente se llama predistribución del ingreso (Cormick, 2012, p. 241).

La política de subsidios debe estudiarse, perfeccionarse respecto a lo realizado desde la presidencia de Kirchner y hasta el 2015, para realmente mejorar la situación de aquellos que más lo necesitan, teniendo en cuentas diferentes categorías o grupos diferenciales de usuarios (beneficiarios de la Asignación Universal por Hijo, estudiantes, personas con capacidades diferentes, jubilados, personal doméstico, etc.).

Este objetivo es el que permitirá que el destino de los subsidios se conduzca hacia aquéllos que más lo necesitan, permitiendo, en consecuencia, un cambio de paradigma en la asignación de recursos que ya se ha iniciado en nuestro país, pasando de la generalización a una efectiva asignación, analizando cada caso.

Si entendemos como lógica y razonable la quita de subsidios a los barrios más adinerados, bien podrían agregarse a este grupo a todos los edificios de categoría del resto de los barrios, o los inmuebles cuyos propietarios tienen ingresos superiores a una cifra determinada. Está claro que en el resto de los barrios existe numerosa cantidad de gente con capacidades de contribuir -o soportar una tarifa más elevada, no subsidiada-. Al respecto, entendemos que debe profundizarse este camino de reorientación de subsidios a aquellos sectores de la sociedad que realmente necesitan de éstos para abonar las tarifas (...) Con el objetivo de posibilitar el acceso a la mayor cantidad de usuarios que accedan a los servicios públicos, compartimos la idea que en su momento llevó al entonces presidente Néstor Kirchner a presentar un Proyecto de Ley estableciendo un "Régimen Nacional de Servicios Públicos" que contemplaba, entre otros, además de tarifas justas y razonables, en su art. 22, un servicio solidario, para garantizar el acceso a hogares indigentes. Más allá de la repercusión que tuvo en su momento, y de las feroces críticas centradas en los efectos negativos que tales medidas tendrían para las inversiones, el Proyecto nunca se convirtió en ley. La reforma constitucional de 1994, en su art. 42, como fue dicho, tuvo un fuerte interés en garantizar la calidad y eficiencia de los servicios públicos, pero nada se dice en cuanto a garantizar el acceso. Evidentemente, se orientan esfuerzos en garantizar la mejora de aquéllos que ya poseen la calidad de usuarios, sin atender al enorme número de personas que ni siquiera acceden al servicio (Cormick, 2012, pp. 245-246).

El Estado tiene el deber de suplir a los privados cuando encuentra una situación excepcional de injusticia social y no debe bajo ningún concepto desatender los requerimientos de los sectores excluidos de este modelo liberal, motivado en la crítica al modelo del "Estado de bienestar" (Maljar, 1998, p. 225).

En esta época denominada de las "post-privatizaciones", dijimos que el Estado que emerge, es un Estado subsidiario, siendo su rol fundamental suplir la iniciativa privada allí donde esta no puede dar respuesta. Surge el modelo donde el Estado, en su rol de suplencia, es el "titular de la responsabilidad social"; 
es decir, allí donde exista desnutrición, falta de vivienda, de acceso a la salud, enfermedades -en fin, pobreza extrema-, el Estado tiene la obligación de intervenir por todos los medios que tenga a su alcance para impedir estos flagelos. Esta también es la tendencia que se viene observando, desde hace un tiempo en el mundo.

Creer que la mano invisible del mercado y la eficiencia de los privados redundarán en mejores servicios públicos y, por ende, en que mayor cantidad de gente tenga acceso a ellos es un error. Ya sucedió y aún sucede. Los servicios deben sustraerse de la lógica mercantil y ser considerados como bienes públicos a disposición de todos los habitantes y no solo de quienes puedan constituirse en consumidores. Y aun cuando la política del Estado sea que estos servicios los presten los privados, se deberá controlar su accionar, sin perder de vista la experiencia respecto a los entes reguladores creados a partir de las privatizaciones que demuestra que no se hizo correctamente (recientemente se acaba de sancionar la Ley 27.541 de Solidaridad Social y Reactivación Productiva en el Marco de la Emergencia Pública cuyo art. 6o, en consonancia con lo expresado respecto a la experiencia de los entes, dice: "Facúltase al Poder Ejecutivo a intervenir administrativamente el Ente Nacional Regulador de Electricidad (ENRE) y el Ente Nacional Regulador del GAS (ENARGAS) por el término de un (1) año").

El mismo Estado, no solo deberá velar por la prestación de calidad y a precios accesibles de los servicios sino que también deberá centrar su atención a la protección ambiental, la seguridad, el derecho a la información y participación ciudadana.

La política de subsidios debe seguir vigente, colaborando con las clases que más lo necesitan para que las mismas logren un pleno desenvolvimiento y crecimiento sostenible, permitiendo acortar las brechas sociales entre los habitantes del país. Habrá que estudiar categorías o formas más efectivas de brindarlos, pero, desde ya no dependiendo de la voluntad de los usuarios, ya que la experiencia del programa "Renuncia Voluntaria al Subsidio" fracasó.

A casi 25 años de la última reforma constitucional, el Estado está en deuda para lograr satisfacer las necesidades de la población que permitan un crecimiento sostenible; y si decidiera prestar estos servicios por sí, deberá hacerlo aun a pérdida, no analizando ganancias cual si fuese una empresa, para tratar de integrar y llegar a zonas donde los privados no invierten, asumiendo su rol de manera objetiva, más allá de condicionamientos políticos, y apegándose al mandato constitucional en cuanto lo hace depositario de la defensa de los derechos de los ciudadanos a los que representa, y permitiendo que los operadores privados obtengan sus beneficios, siempre dentro de un marco de razonabilidad.

En definitiva, y a modo de conclusión, entendemos como positivas las medidas tendientes a reorientar los subsidios con medidas diferenciadoras que generen 
una real distribución del ingreso, teniendo en miras los dos objetivos fundamentales por los cuales, a nuestro entender una actividad es catalogada por su interés público como servicio público: ampliar la red y mejorar la calidad de los servicios, y, por su parte, establecer una tarifa accesible a toda la sociedad para garantizar el efectivo uso del servicio por toda la comunidad (Cormick, 2012, p. 247).

\section{Referencias bibliográficas}

Cormick, D. (2012). Servicios públicos en la actualidad. Hacia políticas de utilización eficiente de los subsidios. Revista Derecho Público, año I, 3. Ediciones Infojus, p. 231, 231-247.

Galina, C. (2009). Constitución, Servicimergencia. Buenos Aires: Ad Hoc.

Garrote, J. (2007). Servicios públicos en la Argentina: desafíos pendientes desde una perspectiva de derechos humanos. Cels. Derechos Humanos en Argentina: Informe 2007. Buenos Aires: Siglo XXI, pp. 371-390.

Limpens, F. (1999). Los Derechos Humanos y su fundamentación filosófica. Revista Electrónica Sinéctica, pp. 1-13. Recuperado de: https://www.redalyc.org/articulo.oa?id=99825994002

Maljar, D. (1998). Intervención del Estado en la prestación de servicios públicos. Buenos Aires: Hammurabi.

\section{Referencias jurisprudenciales}

CSJN, "Centro de Estudios para la Promoción de la Igualdad y la Solidaridad y otros e/ Ministerio de Energía y Minería s/ amparo colectivo", 18 de agosto de 2016.

STJ Corrientes, "Encina de Ibarra, Carmen c/ Aguas de Corrientes S. A", La Ley, 1999-B, 784.

Cámara de Apelaciones Contenciosa Administrativa de Tucumán, Sala I, "Ramos, Elsa Mirta c/ Sociedad Aguas del Tucumán" 25/02/2010, MJJ55634. 